\title{
Digit Span Subtest (WAIS-IV)
}

National Cancer Institute

\section{Source}

National Cancer Institute. Digit Span Subtest (WAIS-IV). NCI Thesaurus. Code C120365.

A subtest of the Wechsler Adult Intelligence Scale, 4th Edition that measures working memory, mental manipulation, cog nitive flexibility, rote memory and learning, attention, and encoding. The subject is asked to recall numbers in the same order presented (digit span forward), reverse order (digit span backward), or recall the numbers in ascending order (digit span sequencing). 